\title{
Editorial
}

\section{Gene therapy for the millenium: in with the new}

The journal Gene Therapy is now more than 5 years old and flourishing along with the clinical and basic research communities active in this field. The volume of work being undertaken in patients and experimental systems continues to increase and we have had to grow with it you will notice the larger size of this year's issues which demonstrates how many authors are now submitting papers of the highest quality to the journal. We aim to increase further the profile of the journal and the impact of our contributors' work with a range of new developments.

The publishers of Gene Therapy are the Nature Publishing Group, a new company which comprises all the Nature titles and the Stockton Press journals. The company is committed to the development of innovative and flexible approaches to publishing for the scientific and medical communities, and we expect this to open up new opportunities for electronic and on-line services for our readers. Access to the spectrum of resources and skills within the organisation will be a major benefit to Gene Therapy as it evolves in the future and we are determined to make the most of the opportunities presented here.

The Editorial Board is an important part of the journal and fresh blood has been introduced to reflect the new areas in gene therapy where we require expertise, advice and imagination. Many board members had been with us since the journal was launched and we salute their efforts in supporting its development over the years. Clearly genetic intervention is beginning to have applications which were unimaginable just a short while ago, with investigators targeting preclinical phases of disease and using genetic technology in innovative approaches to transplantation. We intend to have a rolling programme of recruitment to the Board to ensure that we stay ahead of the growing edges of the field.

We now have a Perspective section in the journal, where current 'hot' or provocative papers will be highlighted. We hope that this forum will prove popular with our readers and that authors will raise their game to compete for this billing!

The Editorial offices now receive more than 400 manuscripts (and rising) a year and clearly we have to disappoint an increasing number of authors as we strive to maintain the standards for publication at the highest quality. We are committed to providing a forum for the best papers, from research articles describing novel platform technologies and experimental models, clinical studies reporting the most significant trials in human subjects, to invited expert reviews on significant issues and growth areas.

The methods for genetic intervention in ameliorating disease processes have expanded in many ways over the past few years, and success in long-term and even regulated expression of transferred genes in vivo using drugsensitive recombinant transcription factor-promoter combinations and tissue-specific promoters has proven feasible. Both nonviral and viral vectors have proved capable of delivery of genes to most tissues in animal models and both types of vectors have gone through many generations of improvements that reduce or eliminate superfluous vector gene expression, vector toxicity and immune destruction of vector-transduced cells. The first significant successes in gene therapy are nearly in hand and the practical use of this therapeutic modality will soon become a reality.

The Editors encourage the submission of innovative papers that contribute studies of new vector systems, novel animal models of disease and methods of gene regulation in vivo. We are also enthusiastic about publishing more research dealing with the 'side-effects' of vector residence in cells, such as changes in cell function and gene expression unrelated to the transferred gene, and fundamental research on location and structure of vector sequences in cells.

The identities of various stem cells in the body from which tissues are replenished are now coming to light. We can expect to see greater use of engineered stem cells for tissue reconstruction in the future. For example, surprising information on the degree of plasticity of bone marrow cells which can act as precursors for blood vessel endothelium, connective tissue and liver suggests new avenues for transplantation research and clinical practice. The burgeoning of this expanded field has prompted the Editors of Gene Therapy to encourage the publication of papers dealing with engineered stem cells as gene therapy vehicles. In the coming year, we welcome such manuscripts including those contributing fundamental information on the biology of these cells as it relates to engineered cell therapies.

$$
\begin{array}{r}
\text { NR Lemoine }{ }^{1} \text { and JC Glorioso }{ }^{2} \\
{ }^{1} \text { Department of Cancer Medicine, } \\
\text { Imperial College School of Medicine, } \\
\text { Hammersmith Hospital, Du Cane Road, } \\
\text { London W12 ONN, UK; and }{ }^{2} \text { Department } \\
\text { of Molecular Genetics and Biochemistry } \\
\text { School of Medicine, University of } \\
\text { Pittsburgh, E1246 Biomedical Science Tower, } \\
\text { Pittsburgh, PA 15261, USA }
\end{array}
$$

